\title{
The Role of Ammonia in Synthesis of Silver Nanoparticles in Skim Natural Rubber Latex
}

\author{
Panu Danwanichakul, Thanawat Suwatthanarak, \\ Chidchanok Suwanvisith, and Duangkamol Danwanichakul
}

Department of Chemical Engineering, Faculty of Engineering, Thammasat University, Pathumthani 12120, Thailand

Correspondence should be addressed to Panu Danwanichakul; dpanu@engr.tu.ac.th

Received 9 March 2016; Accepted 10 April 2016

Academic Editor: Kalimuthu Kalishwaralal

Copyright ( 2016 Panu Danwanichakul et al. This is an open access article distributed under the Creative Commons Attribution License, which permits unrestricted use, distribution, and reproduction in any medium, provided the original work is properly cited.

\begin{abstract}
Silver nanoparticles (AgNPs) were synthesized in skim natural rubber latex, the by-product from concentrated latex production. The role of ammonia was investigated by varying the concentration to be $0.217,0.362,0.377,0.392$, and $0.406 \mathrm{wt} \%$. The emergence of AgNPs was detected by UV-visible spectrophotometer and electrical conductivity meter. Upon increasing ammonia concentration, the ABS peak increased to a maximum and slightly shifted to a higher wavelength and then it decreased afterward and slightly shifted to a lower wavelength. The shift of the ABS peak was consistent with the conductivity result. The kinetic model was proposed to explain the competition between the reducing effect and size-controlling effect of ammonia. The reducing effect seemed to dominate in the low range of concentration while the size-controlling effect via the formation of $\mathrm{Ag}\left(\mathrm{NH}_{3}\right)_{2}{ }^{+}$complex ion was important in the higher range. The TEM figures evidently confirmed the effects.
\end{abstract}

\section{Introduction}

Fresh natural rubber latex (FNRL) is a colloidal system of cis-1,4-polyisoprene particles suspended in serum. It usually contains about $35 \mathrm{wt} \%$ dry rubber content (DRC), $2.0 \mathrm{wt} \%$ protein, $1.5 \mathrm{wt} \%$ carbohydrates, and $1.3 \mathrm{wt} \%$ lipids [1]. After being tapped, it coagulates and rots quickly; thereby adding ammonia $\left(\mathrm{NH}_{3}\right)$ as a preservative is conventionally necessary. When FNRL is centrifuged, concentrated latex with $60 \mathrm{wt} \%$ DRC as the main product is obtained together with skim natural rubber latex (SNRL) with $4-7 \mathrm{wt} \%$ DRC as a byproduct. Concentrated latex is used to produce medical gloves and other dipped products, whereas skim latex is used to produce low-valued skim crepe and skim block.

Silver nanoparticles (AgNPs) have been utilized for many purposes including catalysis, sensors, photonics, superconductors, and environmental and antibacterial activities [24]. The latter purpose has been adopted in many commercial appliances such as air conditioning systems and washing machines. Even natural rubber products such as foams need an antibacterial agent [5]. Basically, nanoparticles including AgNPs are formed by a reduction reaction in colloidal systems, where a precursor of metal cations, a reducing agent, and a capping agent or stabilizing agent are all present. In general, such synthesis involves the use of hazardous chemicals so turning to less toxic or nontoxic biomaterials has been captivating researchers as a way towards green synthesis.

Our group has recently focused on AgNPs synthesis in skim natural rubber latex at room temperature $\left(26^{\circ} \mathrm{C}\right)$ and found that glucose and ammonia could increase the size of AgNPs while protein could prohibit the growth [3], similar to what was found for the synthesis in concentrated latex at $100^{\circ} \mathrm{C}$ as reported previously by Guidelli et al. [6]. As the properties of nanoparticles rely on their sizes, there have been many efforts to control the growth. For instance, Zielinska et al. investigated the effect of silver precursors, stabilizers, and reducing agents on particle size and shape of AgNPs and color of the suspension [7]. Previous studies have reported that many natural compounds can act as a capping as well as reducing agent in the green synthesis of AgNPs such as $J$. curcas [8], Rhodomyrtus tomentosa acetone extract [4], and hydroxypropyl starch [9].

Some reported the effect of ammonia with or without other chemicals on size controlling of AgNPs since 
ammonia could simply form a complex ion with silver ion as $\mathrm{Ag}\left[\mathrm{NH}_{3}\right]_{2}{ }^{+}[10-14]$. The complex ion could slow the rate of reduction since it is a weaker oxidizing agent than $\mathrm{Ag}^{+}$as reported by Oluwafemi et al. [13]. Gorup et al. proposed that ammonia should be added after the formation of fine nuclei to control growth process and the absorbance of the sample with ammonia was observed to increase much less slowly along the reaction time than that without ammonia [11].

Regarding the skim natural rubber latex, ammonia is already left over in the system, and its amount could be independently varied apart from other nonrubber components either by evaporating or by adding more. As mentioned above, our previous results showed that adding ammonia increased the number and size of AgNPs while others reported the retarding effect of ammonia. Therefore, in this work, the role of ammonia was clarified by investigating its effect on the size of the obtained AgNPs for various ammonia concentrations in the latex along with the proposed simplified kinetics for the production of AgNPs.

\section{Materials and Experimental}

2.1. Materials. SNRL with $4.345 \mathrm{wt} \%$ DRC was obtained from Thai Eastern Group, Thailand. Silver nitrate and 36.5-38.0 wt\% hydrochloric acid $(\mathrm{HCl})$ were supplied by Merck Ltd., Germany. 28.0-30.0 wt\% ammonium hydroxide $\left(\mathrm{NH}_{4} \mathrm{OH}\right)$ as a source of ammonia was from J.T.Baker Ltd., USA. Methyl red indicator was from Suksapan Panit, Thailand. Dialysis tube with molecular weight cut-off of $12-14 \mathrm{kDa}$ was from Spectrum Laboratories, Inc., USA. All chemicals were used without further purification.

\subsection{Experimental}

2.2.1. Preparation of Skim Latex with Various Ammonia Concentrations. The initial $\mathrm{NH}_{3}$ concentration of skim latex was $0.362 \mathrm{wt} \%$. To obtain $0.217 \mathrm{wt} \% \mathrm{NH}_{3}, 10 \mathrm{~mL} \mathrm{SNRL}$ was left at $26^{\circ} \mathrm{C}$ for $10 \mathrm{~min}$ to evaporate $\mathrm{NH}_{3}$. To obtain $0.377,0.39$, and $0.406 \mathrm{wt} \% \mathrm{NH}_{3}, 5,10$, and $20 \mu \mathrm{L}$ of $\mathrm{NH}_{4} \mathrm{OH}$ solution were added to $10 \mathrm{~mL}$ SNRL, respectively. The $\mathrm{NH}_{3}$ concentration was determined according to ISO 125:2011, a method for the determination of the alkalinity of natural rubber latex concentrate. The mixture of $5.0 \pm 0.5 \mathrm{~g}$ SNRL and $200 \mathrm{~mL}$ distilled water was titrated with $0.1 \mathrm{~N} \mathrm{HCl} \mathrm{using} \mathrm{methyl} \mathrm{red} \mathrm{as}$ the indicator. The end point was when the color changes from yellow to pink. The $\mathrm{NH}_{3}$ concentration is calculated from

$$
\% \text { wt } \mathrm{NH}_{3}=\frac{1.7 \times N \times V}{m} \text {. }
$$

Here, $N$ and $V$ are normality and volume of $\mathrm{HCl}$ solution $(\mathrm{mL})$ and $m$ is latex mass $(\mathrm{g})$.

2.2.2. AgNPs Synthesis and Characterisation. $8 \mathrm{mM} \mathrm{AgNO}_{3}$ stock solution was mixed with SNRL to obtain the suspension with $1.2 \mathrm{mM} \mathrm{Ag}^{+}$and $0.05 \mathrm{wt} \%$ DRC before stirring at $100 \mathrm{rpm}$ for $45 \mathrm{~min}$ at $26^{\circ} \mathrm{C}$. It was then transferred to a dialysis tube immersed in $330 \mathrm{~mL}$ distilled water for $24 \mathrm{~h}$ with slow stirring to retard the reaction. On synthesis day and after $24 \mathrm{~h}$ dialysis, the formation of AgNPs in SNRL was studied by visible spectrophotometer (METASH, V-5100) at 340$580 \mathrm{~nm}$. Suspension conductivity was checked with electrical conductivity meter (HM, COM-100). Transmission electron microscope (TEM) (JEOL JEM-2010) was applied to study the morphology of AgNPs. ImageJ, a program for image analyzer, was applied to measure all the sizes of AgNPs by calibrating with the scale provided in the TEM micrographs and finally the average sizes of AgNPs were obtained for each figure.

\section{Results and Discussion}

A simplified scheme was proposed as follows. $\mathrm{Ag}^{+}$is from $\mathrm{AgNO}_{3}$ precursor (see (2)) and the reducing agents could be any organic substance in the latex (see (3)). $\mathrm{NH}_{3}$ itself could also be a reducing agent or could assist in hydrolysis of organic substances in the latex [15] so it directly or indirectly increases the amount of reducing agents (see (4)). $\mathrm{NH}_{3}$ also forms the complex ion with $\mathrm{Ag}^{+}$through the equilibrium reaction (see (5)) and this ion could also act as the oxidizing agent to form $\mathrm{Ag}^{0}$ (see (6)):

$$
\begin{aligned}
& \mathrm{AgNO}_{3} \longrightarrow \mathrm{Ag}^{+}+\mathrm{NO}_{3}^{-} \\
& \mathrm{Ag}^{+}(\mathrm{aq})+\text { organic substances }(\mathrm{aq}) \stackrel{k_{1}}{\longrightarrow} \mathrm{Ag}^{0}+\text { other products } \\
& \mathrm{Ag}^{+}(\mathrm{aq})+\mathrm{NH}_{3}(\mathrm{aq}) \stackrel{k_{2}}{\longrightarrow} \mathrm{Ag}^{0}+\text { other products } \\
& \mathrm{Ag}^{+}(\mathrm{aq})+2 \mathrm{NH}_{3}(\mathrm{aq}) \underset{k_{4}}{\stackrel{k_{3}}{\rightleftarrows}} \mathrm{Ag}\left(\mathrm{NH}_{3}\right)_{2}^{+}(\mathrm{aq}) \\
& \mathrm{Ag}\left(\mathrm{NH}_{3}\right)_{2}^{+}(\mathrm{aq})+\text { organic substances }(\mathrm{aq}) \stackrel{k_{5}}{\longrightarrow} \mathrm{Ag}^{0}+\text { other products }
\end{aligned}
$$

Each reaction is governed by its rate constant. It is further assumed that $\mathrm{Ag}^{0}$ atoms are produced first and then they combine to form larger particles or nanoparticles (AgNPs). The higher the production rate of $\mathrm{Ag}^{0}$ is, the higher the 


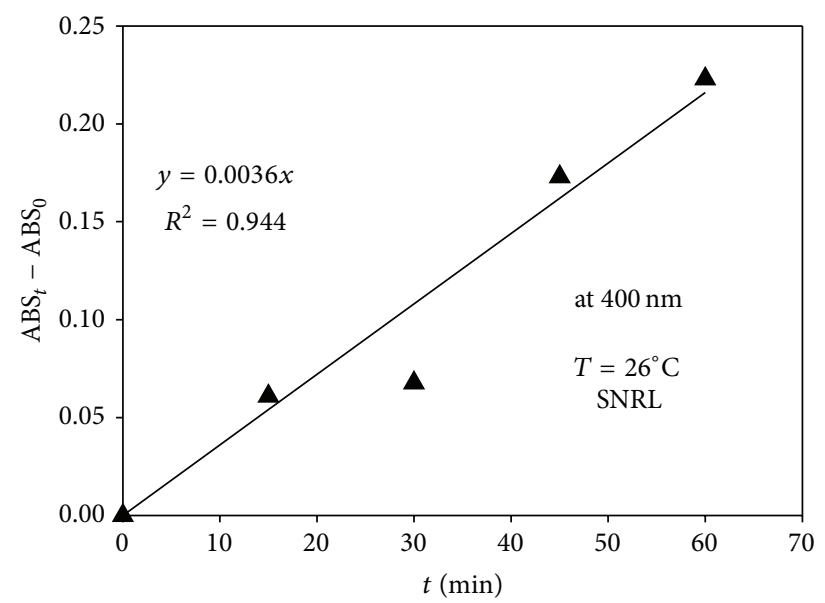

(a)

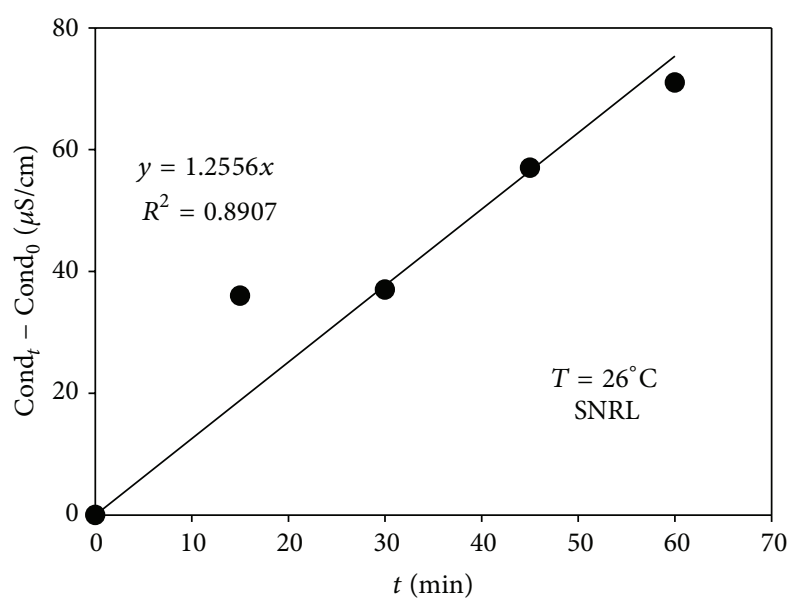

(b)

FIgURE 1: (a) Absorbance at $400 \mathrm{~nm}$ and (b) conductivity of the suspension along the reaction time.

AgNPs production rate will be. For example, for dimers to be generated,

$$
\mathrm{Ag}^{0}+\mathrm{Ag}^{0} \stackrel{k_{6}}{\longrightarrow} \mathrm{Ag}_{2}
$$

and for the production of larger particles,

$$
\mathrm{Ag}_{n}+\mathrm{Ag}_{m} \longrightarrow \mathrm{Ag}_{n+m}
$$

It was suggested by Khan et al. that the reduction was of the first order with respect to $\left[\mathrm{Ag}^{+}\right]$and the reducing agent [16] so it is reasonable to write the rate equations for all silver species as

$$
\begin{aligned}
\frac{d\left[\mathrm{Ag}^{+}\right]}{d t}= & -k_{1}\left[\mathrm{Ag}^{+}\right]-k_{2}\left[\mathrm{Ag}^{+}\right]\left[\mathrm{NH}_{3}\right] \\
& -k_{3}\left[\mathrm{Ag}^{+}\right]\left[\mathrm{NH}_{3}\right]^{2} \\
& +k_{4}\left[\mathrm{Ag}\left(\mathrm{NH}_{3}\right)_{2}^{+}\right] \\
\frac{d\left[\mathrm{Ag}\left(\mathrm{NH}_{3}\right)_{2}^{+}\right]}{d t}= & k_{3}\left[\mathrm{Ag}^{+}\right]\left[\mathrm{NH}_{3}\right]^{2} \\
& -k_{4}\left[\mathrm{Ag}\left(\mathrm{NH}_{3}\right)_{2}^{+}\right] \\
& -k_{5}\left[\mathrm{Ag}\left(\mathrm{NH}_{3}\right)_{2}^{+}\right] \\
\frac{d\left[\mathrm{Ag}^{0}\right]}{d t}= & k_{1}\left[\mathrm{Ag}^{+}\right]+k_{2}\left[\mathrm{Ag}^{+}\right]\left[\mathrm{NH}_{3}\right] \\
& +k_{4}\left[\mathrm{Ag}\left(\mathrm{NH}_{3}\right)_{2}^{+}\right]
\end{aligned}
$$

The value of complex formation constant, $K_{f}=$ $\left[\mathrm{Ag}\left(\mathrm{NH}_{3}\right)_{2}{ }^{+}\right] /\left[\mathrm{Ag}^{+}\right]\left[\mathrm{NH}_{3}\right]^{2}$, is so high that the left hand side of (10) could be assumed to be close to zero. From (8)-(10) together with the fact that total mass of all silver species must be conserved, which is related to the initial concentration of silver ions, $\left[\mathrm{Ag}^{+}\right]_{0}$, one could obtain that

$$
\left[\mathrm{Ag}^{0}\right]=\left[\mathrm{Ag}^{+}\right]_{0}\left(1-e^{-k_{\mathrm{all}} t}\right)
$$

where

$$
k_{\mathrm{all}}=\frac{k_{1}+k_{2}\left[\mathrm{NH}_{3}\right]+k_{5} K_{f}\left[\mathrm{NH}_{3}\right]^{2}}{1+K_{f}\left[\mathrm{NH}_{3}\right]^{2}} .
$$

When (12) is applied to reaction (7), $\left[\mathrm{Ag}_{2}\right]$ could be obtained as

$$
\left[\mathrm{Ag}_{2}\right]=k_{6}\left[\mathrm{Ag}^{+}\right]_{0}^{2}\left[t+\frac{2 e^{-k_{\text {all }} t}}{k_{\text {all }}}-\frac{e^{-2 k_{\text {all }} t}}{2 k_{\text {all }}}-\frac{3}{2 k_{\text {all }}}\right] .
$$

In reality, the growth kinetics of nanoparticles is much more complex than (14) and it may follow Smoluchowski's kinetics [17]. However, this simple scheme could essentially imply that the growth rate of nanoparticles depends on $k_{\text {all }}$. At a small time when $\left[\mathrm{NH}_{3}\right]$ does not change much with time, the nucleation as well as growth rate increases with increasing $k_{\text {all }}$. Therefore, initial $\left[\mathrm{NH}_{3}\right]$ obviously influences the growth rate of AgNPs as described by (13).

The kinetic results of AgNPs synthesis in diluted SNRL are shown in Figure 1. Up to $60 \mathrm{~min}, \mathrm{ABS}$ at $400 \mathrm{~nm}$ and conductivity still increased linearly with time, consistent with [11] in which the ABS linearly increased up to 8 minutes after the addition of $\mathrm{NH}_{3}$. According to (14), $\left[\mathrm{Ag}_{2}\right]$ increases linearly with time when time is small or $k_{\text {all }}$ is large. Therefore, the long range of linearity in our synthesis implied the high value of $k_{\text {all }}$, possibly attributable to high concentration of natural reducing agents in skim natural rubber latex.

The role of ammonia in the synthesis of AgNPs in SNRL is first displayed in Figure 2. When $\left[\mathrm{NH}_{3}\right]$ increased from 0.217 to $0.385 \mathrm{wt} \%$, the ABS peak increased to a maximum and its position shifted to a larger wavelength implying the formation of more and larger AgNPs. However, when $\left[\mathrm{NH}_{3}\right]$ increased from 0.377 to $0.406 \mathrm{wt} \%$, the peak was lower and the position shifted to a smaller wavelength indicating fewer and smaller AgNPs. In addition, the ABS peaks of suspensions after $24 \mathrm{~h}$ dialysis were greater than those on synthesis day indicating more particles formed from remaining reactants after dialysis. 


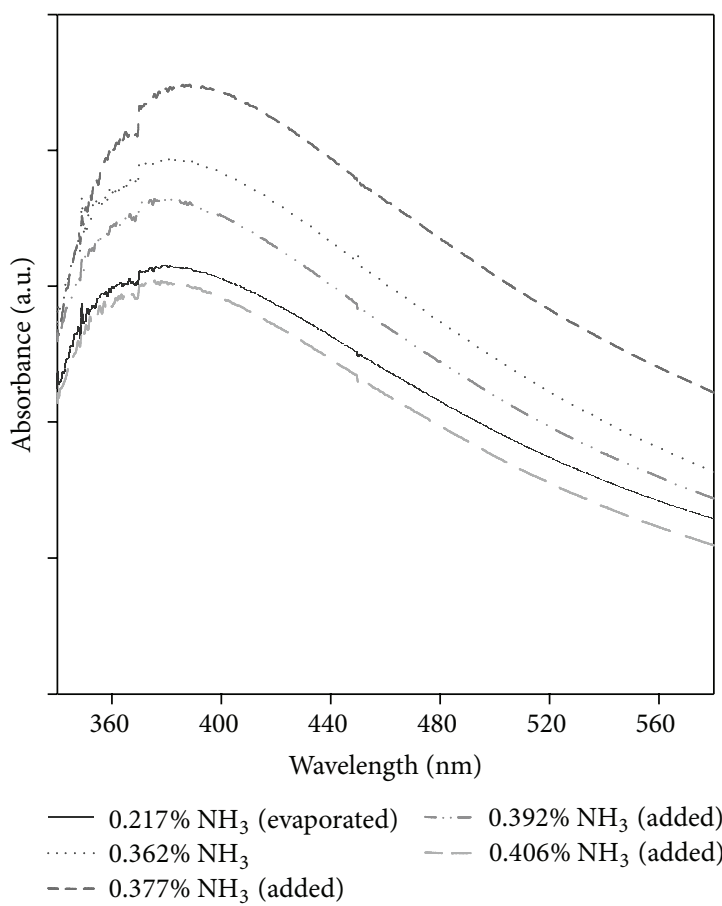

(a)

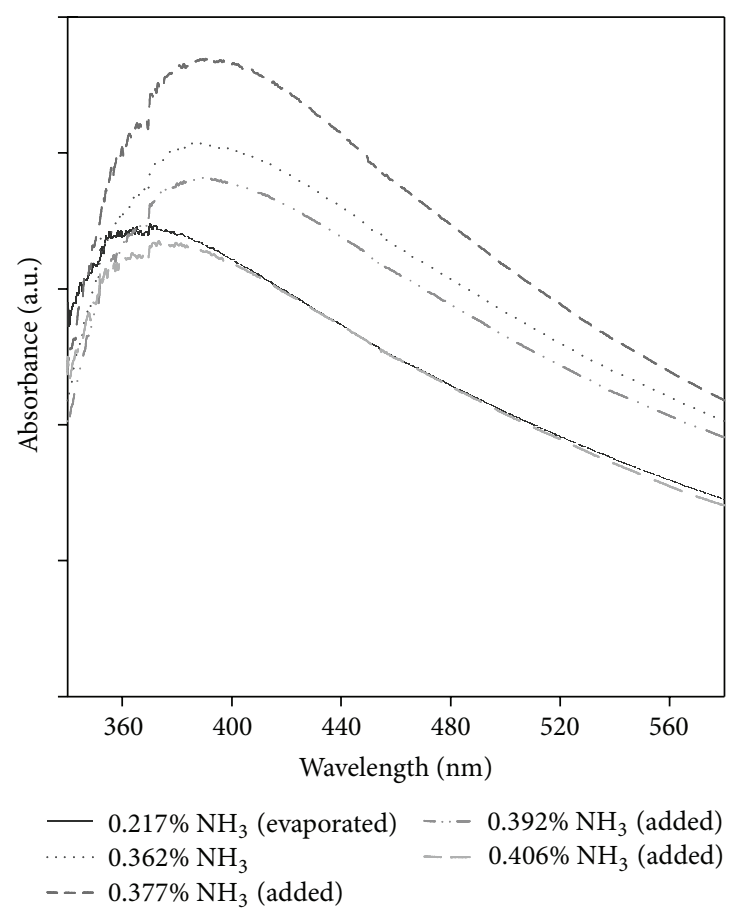

(b)

FIGURE 2: Absorbance of AgNPs suspension (a) on synthesis day and (b) after dialysis.

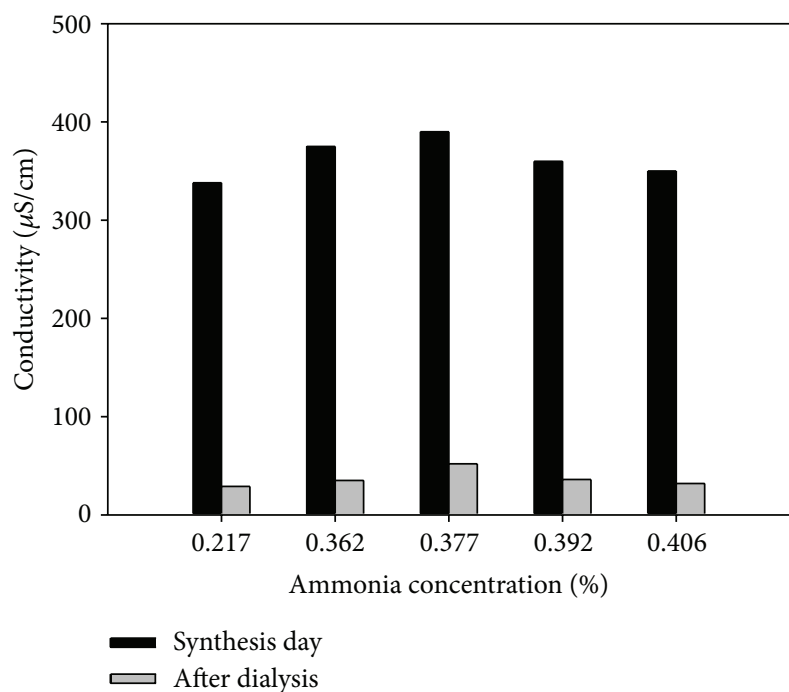

FIGURE 3: The conductivity reached the maximum and then dropped along increasing ammonia concentration.

The ABS results were confirmed with the conductivity results in Figure 3. The consistency between both results has been recently reported by Suwatthanarak et al. [3]. The increase of conductivity may result from attractive interactions among metallic particles (AgNPs) and metallic ions implying the possibility of increasing number of AgNPs. After $24 \mathrm{~h}$ dialysis, the same trend was seen but the values were much lower because small molecules and ions were removed.
The morphology of AgNPs is shown in Figure 4 and the effect of ammonia concentration on the size of AgNPs is shown in Figure 5. Upon increasing $\left[\mathrm{NH}_{3}\right]$ from 0.217 to 0.362 and $0.377 \mathrm{wt} \%$, the average size of AgNPs increased from 10 to 12 and $150 \mathrm{~nm}$, respectively, and then decreased to $10 \mathrm{~nm}$ when $\left[\mathrm{NH}_{3}\right]$ was $0.406 \mathrm{wt} \%$. This evidence is in good accordance with the ABS and conductivity analyses. Considering (13), if $\left[\mathrm{NH}_{3}\right]$ is small enough to make $K_{f}\left[\mathrm{NH}_{3}\right]^{2}<1$, all terms in the numerator are important showing that $k_{\text {all }}$ will increase with increasing $\left[\mathrm{NH}_{3}\right]$ and if $K_{f}\left[\mathrm{NH}_{3}\right]^{2}>1, k_{\text {all }}$ will decrease with increasing $\left[\mathrm{NH}_{3}\right]$. Ammonia could, thus, play a role not only in increasing the reaction rate but also in retarding the growth of particles when it was used in different range of concentration.

\section{Conclusion}

Ammonia in SNRL could act as a reducing agent as well as the size-controlling agent when forming the complex ion, $\mathrm{Ag}\left(\mathrm{NH}_{3}\right)_{2}{ }^{+}$. According to the proposed kinetics, ammonia could increase or decrease $k_{\text {all }}$ affecting the final rate of nucleation and growth of AgNPs since the dominant effect will govern the kinetics. In the region of low $\left[\mathrm{NH}_{3}\right]$, the effect of ammonia as a reducing agent was dominant while, in the region of higher $\left[\mathrm{NH}_{3}\right]$, the size-controlling effect was dominant. This knowledge could be useful for the design of experiment involving the use of ammonia to control the size of nanoparticles which are in fact not limited to AgNPs provided that metal cations could form complex ions with ammonia. 

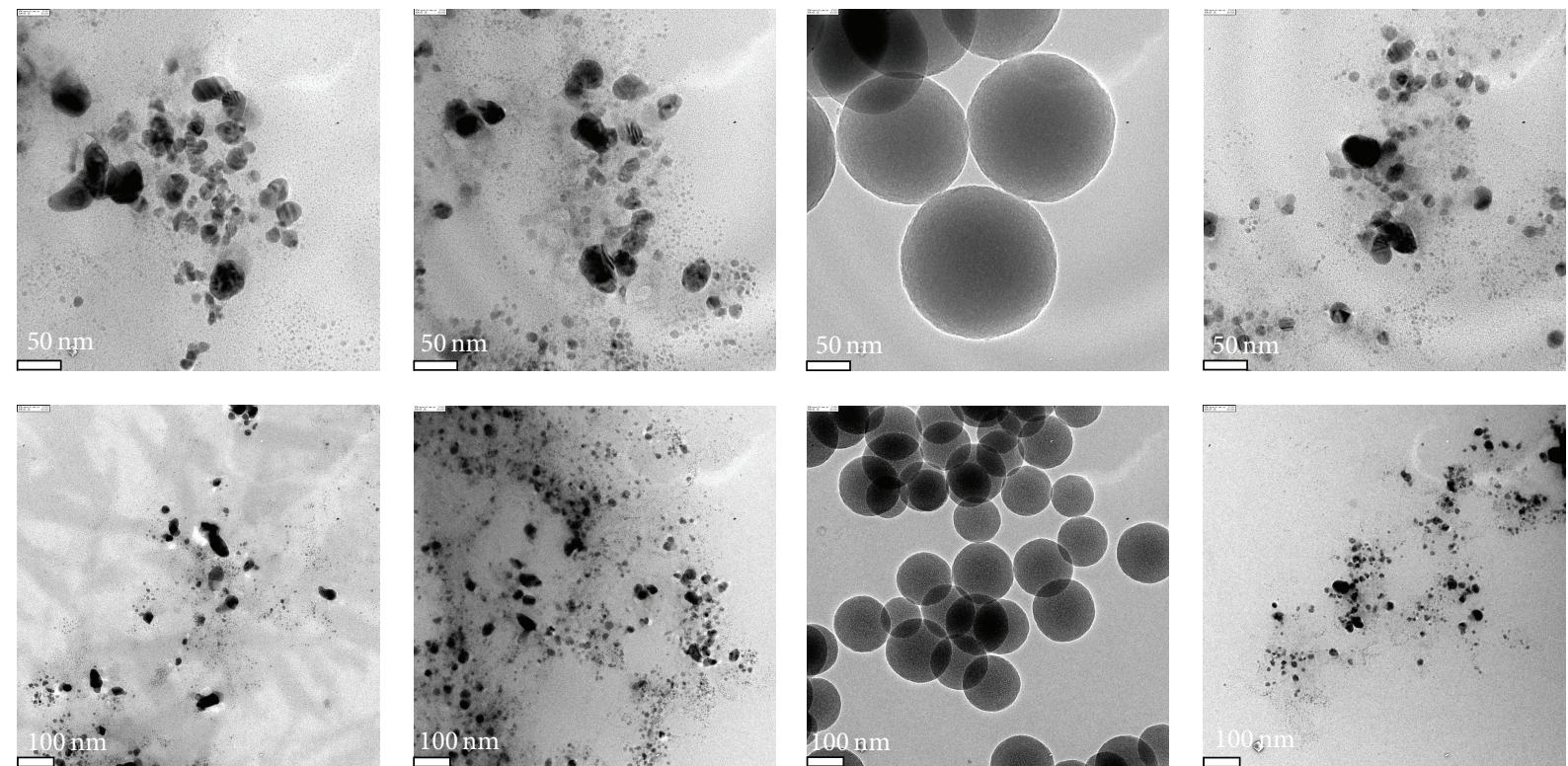

$0.217 \% \mathrm{NH}_{3}$

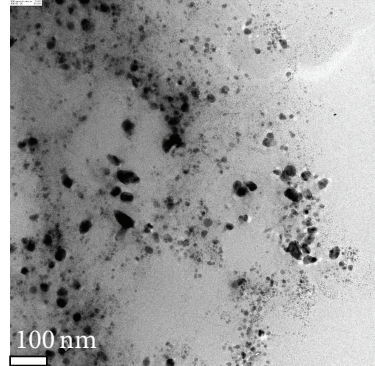

$0.362 \% \mathrm{NH}_{3}$

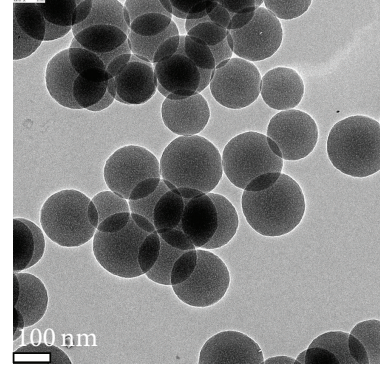

$0.377 \% \mathrm{NH}_{3}$

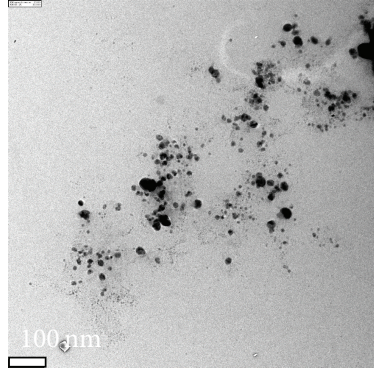

$0.406 \% \mathrm{NH}_{3}$

FIgURE 4: TEM micrographs of AgNPs synthesized in SNRL on synthesis day.

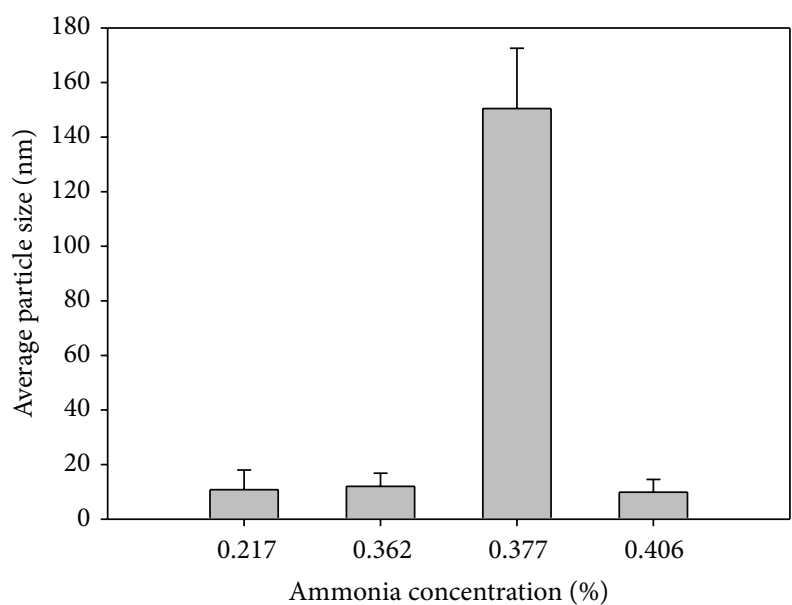

FIGURE 5: The effect of ammonia concentration on the average particle size of AgNPs synthesized in SNRL on synthesis day.

\section{Competing Interests}

The authors declare that they have no competing interests.

\section{Acknowledgments}

The financial support from the government funding through the National Research Council of Thailand (NRCT) and Thammasat University under Contract no. 016/2558 for the fiscal year 2015 is gratefully acknowledged.

\section{References}

[1] F. W. Perrellaa and A. A. Gasparib, "Natural rubber latex protein reduction with an emphasis on enzyme treatment," Methods, vol. 27, no. 1, pp. 77-86, 2002.
[2] L. Sintubin, W. De Windt, J. Dick et al., "Lactic acid bacteria as reducing and capping agent for the fast and efficient production of silver nanoparticles," Applied Microbiology and Biotechnology, vol. 84, no. 4, pp. 741-749, 2009.

[3] T. Suwatthanarak, B. Than-ardna, D. Danwanichakul, and P. Danwanichakul, "Synthesis of silver nanoparticles in skim natural rubber latex at room temperature," Materials Letters, vol. 168, pp. 31-35, 2016.

[4] S. Shankar, J. Chorachoo, L. Jaiswal, and S. P. Voravuthikunchai, "Effect of reducing agent concentrations and temperature on characteristics and antimicrobial activity of silver nanoparticles," Materials Letters, vol. 137, pp. 160-163, 2014.

[5] W. G. I. U. Rathnayake, H. Ismail, A. Baharin, A. G. N. D. Darsanasiri, and S. Rajapakse, "Synthesis and characterization of nano silver based natural rubber latex foam for imparting antibacterial and anti-fungal properties," Polymer Testing, vol. 31, no. 5, pp. 586-592, 2012.

[6] E. J. Guidelli, A. P. Ramos, M. E. D. Zaniquelli, and O. Baffa, "Green synthesis of colloidal silver nanoparticles using natural rubber latex extracted from Hevea brasiliensis," Spectrochimica Acta Part A: Molecular and Biomolecular Spectroscopy, vol. 82, no. 1, pp. 140-145, 2011.

[7] A. Zielinska, E. Skwarek, A. Zaleska, M. Gazda, and J. Hupka, "Preparation of silver nanoparticles with controlled particle size," Procedia Chemistry, vol. 1, no. 2, pp. 1560-1566, 2009.

[8] H. Bar, D. K. Bhui, G. P. Sahoo, P. Sarkar, S. P. De, and A. Misra, "Green synthesis of silver nanoparticles using latex of Jatropha curcas," Colloids and Surfaces A: Physicochemical and Engineering Aspects, vol. 339, no. 1-3, pp. 134-139, 2009.

[9] M. H. El-Rafie, M. E. El-Naggar, M. A. Ramadan, M. M. G. Fouda, S. S. Al-Deyab, and A. Hebeish, "Environmental synthesis of silver nanoparticles using hydroxypropyl starch and their characterization," Carbohydrate Polymers, vol. 86, no. 2, pp. 630-635, 2011.

[10] L. Sun, Z. Zhang, and H. Dang, "A novel method for preparation of silver nanoparticles," Materials Letters, vol. 57, no. 24-25, pp. 3874-3879, 2003. 
[11] L. F. Gorup, E. Longo, E. R. Leite, and E. R. Camargo, "Moderating effect of ammonia on particle growth and stability of quasi-monodisperse silver nanoparticles synthesized by the Turkevich method," Journal of Colloid and Interface Science, vol. 360, no. 2, pp. 355-358, 2011.

[12] M. Jose and M. Sakthivel, "Synthesis and characterization of silver nanospheres in mixed surfactant solution," Materials Letters, vol. 117, pp. 78-81, 2014.

[13] O. S. Oluwafemi, N. Vuyelwa, M. Scriba, and S. P. Songca, "Green controlled synthesis of monodispersed, stable and smaller sized starch-capped silver nanoparticles," Materials Letters, vol. 106, pp. 332-336, 2013.

[14] Z. Khan, J. I. Hussain, S. Kumar, A. A. Hashmi, and M. A. Malik, "Silver nanoparticles: green route, stability and effect of additives," Journal of Biomaterials and Nanobiotechnology, vol. 2, no. 4, pp. 390-399, 2011.

[15] S. Santipanusopon and S. Riyajan, "Effect of field natural rubber latex with different ammonia contents and storage period on physical properties of latex concentrate, stability of skim latex and dipped film," Physics Procedia, vol. 2, no. 1, pp. 127-134, 2009.

[16] Z. Khan, S. A. Al-Thabaiti, F. M. Al-Nowaiser, A. Y. Obaid, A. O. Al-Youbi, and M. A. Malik, "Kinetics of silver nanoparticle growth in aqueous polymer solutions: 1st Nano Update," Arabian Journal of Chemistry, vol. 5, no. 4, pp. 453-459, 2012.

[17] S. Pankavich, Z. Shreif, and P. Ortoleva, "Multiscaling for classical nanosystems: derivation of Smoluchowski \& FokkerPlanck equations," Physica A: Statistical Mechanics and Its Applications, vol. 387, no. 16-17, pp. 4053-4069, 2008. 

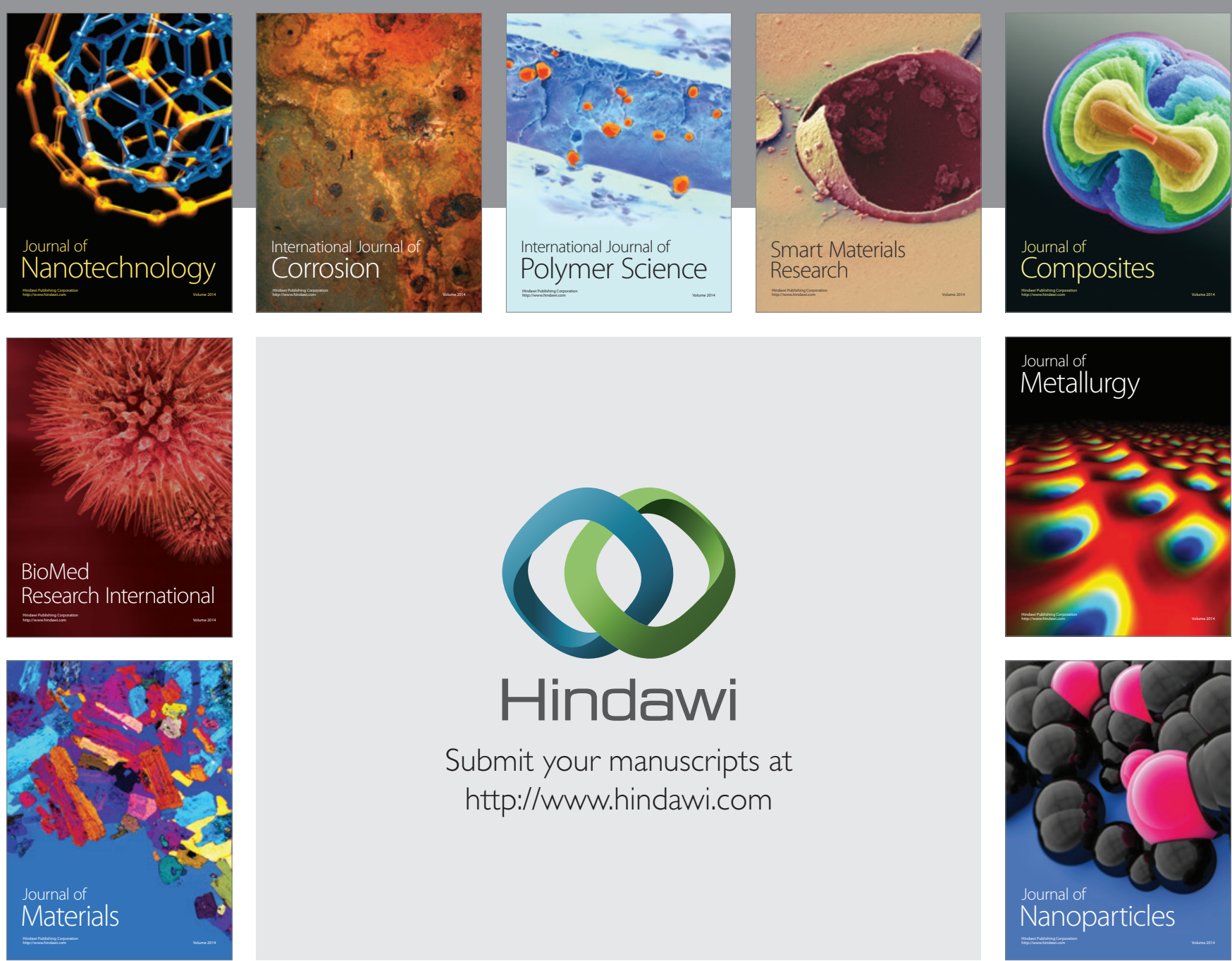

\section{Hindawi}

Submit your manuscripts at

http://www.hindawi.com

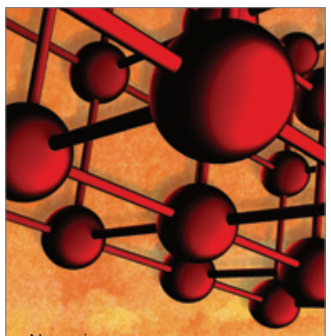

Materials Science and Engineering
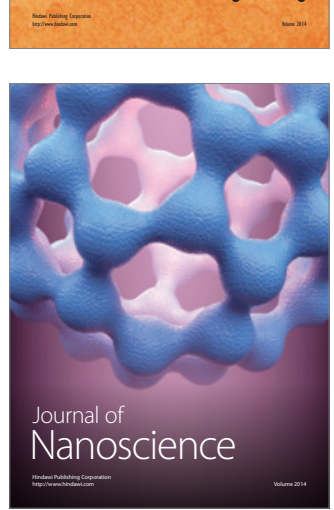
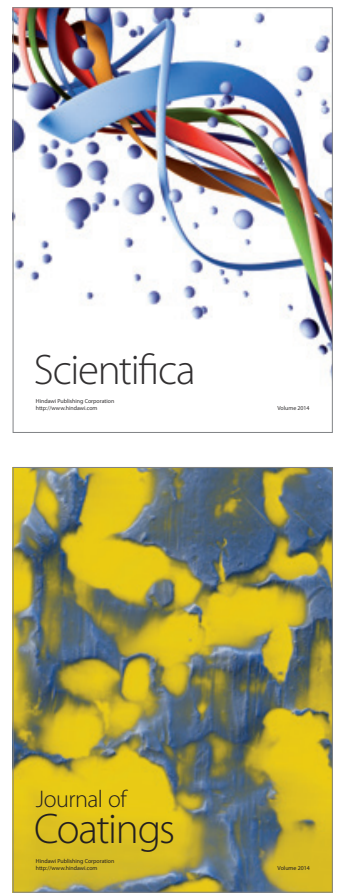
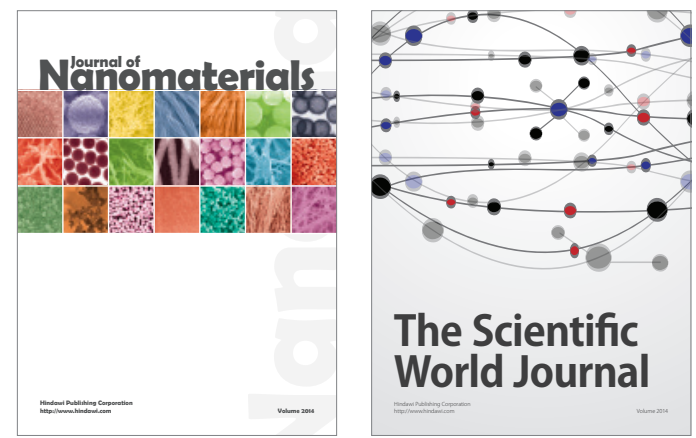

The Scientific World Journal
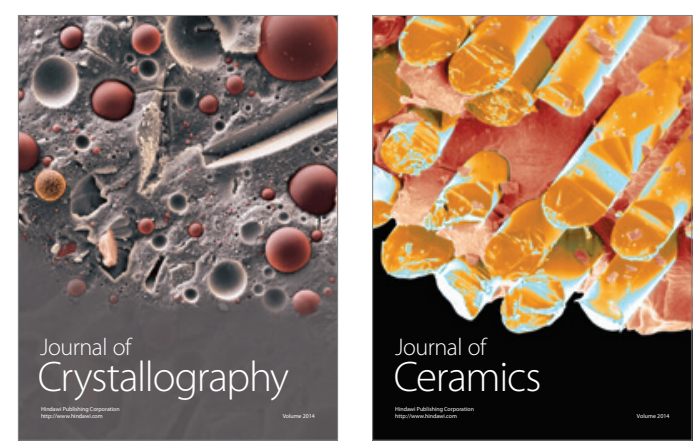
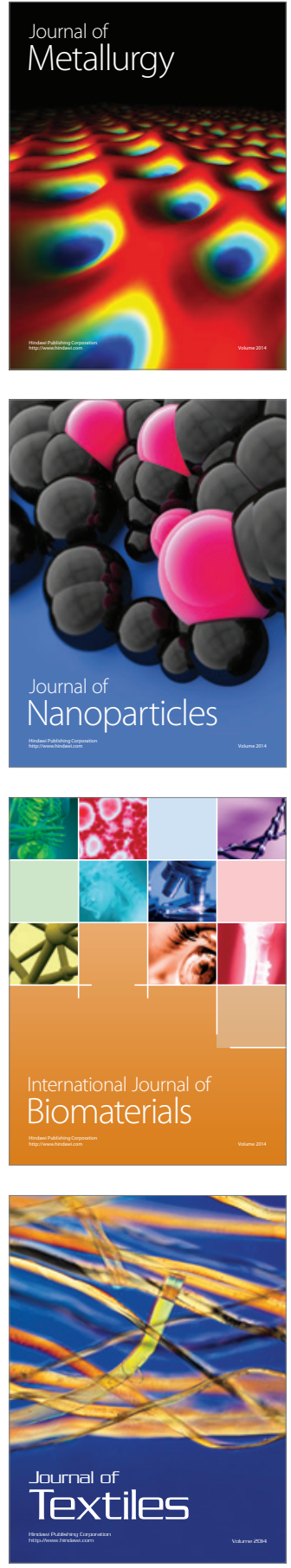